JKM (Jurnal Kebidanan Malahayati),Vol 7,No.2.April 2021,

ISSN (Print) 2476-8944 ISSN (Online) 2579-762X, Hal 155-160

\title{
EFEKTIFITAS AROMATHERAPY UAP LAVENDER DAN PIJAT OKSITOSIN TERHADAP PRODUKSI ASI PADA IBU NIFAS
}

\author{
Fadjriah Ohorella ${ }^{* *}$, Mudyawati Kamaruddin ${ }^{2 *}$, Nahira ${ }^{3}$, Nurhidayat Triananinsi ${ }^{4}$ \\ 1,3,4Program Studi Kebidanan, Universitas Megarezky M akassar 90234, Indonesia \\ 2Division of Health Science, Graduate School of Medical Sciences, Kanazawa University \\ *Korespondensi e-mail: mudya07@gmail.com
}

\section{ABSTRACT: EFFECTIVENESS OF LAVENDER STEAM AROMATHERAPY AND OXYTOCIN MASSAGE IN BREAST MILK DEVELOPMENT IN POSTPARTUM MOTHERS}

Background: Breast milk (ASI) is a natural nutrient with the most suitable nutritional content for optimal growth. The reasons that cause the failure to provide exclusive breastfeeding are both mother and baby factors, as well as psychological conditions due to postpartum exhaustion may affect lactation. One of the nonpharmacological treatments to help postpartum mothers still feel comfortable and relaxed so that they can have a calming effect and help make breast milk smooth is by offering oxytocin massage (OM) and lavender steam aromatherapy (LSA) to postpartum mothers.

Purpose: The purpose of this study was to determine the efficacy of steam aromatherapy stimulation and oxytocin massage in milk production.

Methods: The research design used was the post-test-only design. The sample in this study consisted of 30 postpartum Primipara mothers with the sampling technique using purposive sampling. Data were analyzed using the T Independent Test.

Results: The findings of the univariate analysis showed that more respondents were over 25 years of age (73\%), most recently graduated from high school (67\%), and did not have a job (57\%). bivariate analysis showed that OM intervention therapy in postpartum mothers was more efficient in the development of breast milk with a standard deviation of 6.60591 compared to the intervention of $L S A(S D=9.74435)$.

Conclusion: It can be concluded that relaxation of oxytocin massage and Lavender steam aromatherapy for postpartum mothers in Makassar Health Centre, South Sulawesi, both of which have a relaxing effect and help postpartum mothers to smooth breast milk. However, in this study OM is more effective in accelerating the development of breast milk in postpartum mothers rather than intervention of LSA.

Suggestion Oxytocin massage is more effective in accelerating the development of breast milk in postpartum mothers, therefore health workers, especially midwives are advised to use oxytocin relaxation massage while offering Lavender steam aromatherapy as an alternative method to help postpartum mothers encourage breast milk production .

Keywords: Lavender Steam Aromateraphy; Oxytocin Massage; Breast Milk Production

\section{ABSTRAK}

Latar Belakang: Air susu ibu (ASI) merupakan nutrisi alami dengan kandungan nutrisi yang paling sesuai untuk pertumbuhan yang optimal. Alasan yang menjadi penyebab kegagalan pemberian ASI eksklusif adalah faktor ibu dan bayi, serta kondisi psikologis akibat kelelahan pasca melahirkan dapat mempengaruhi laktasi. Salah satu penanganan non farmakologis untuk membantu ibu nifas tetap nyaman dan rileks sehingga dapat memberikan efek menenangkan dan membantu melancarkan ASI adalah dengan pemberian lavender steam aromatherapy (LSA) dan pijat oksitosin (OM) kepada ibu nifas.

Tujuan: Untuk mengetahui khasiat stimulasi uap aromaterapi dan pijat oksitosin dalam produksi ASI.

Metode: Desain penelitian yang digunakan adalah post-test-only design. Sampel dalam penelitian ini terdiri dari 30 ibu primipara nifas dengan teknik pengambilan sampel menggunakan purposive sampling. Data dianalisis menggunakan Uji Independen T.

Hasil: Temuan analisis univariat menunjukkan bahwa lebih banyak responden berusia di atas 25 tahun (73\%), paling akhir tamat SMA (67\%), dan tidak memiliki pekerjaan (57\%). Analisis bivariat menunjukkan bahwa terapi intervensi OM pada ibu postpartum lebih efisien dalam perkembangan ASI dengan standar deviasi 6,60591 dibandingkan dengan intervensi LSA (SD = 9,74435).

Kesimpulan: Dapat disimpulkan bahwa relaksasi pijat oksitosin dan aromaterapi uap lavender pada ibu 
nifas di Puskesmas Makassar, Sulawesi Selatan, keduanya memiliki efek relaksasi dan membantu ibu nifas melancarkan ASI. Namun pada penelitian ini OM lebih efektif dalam mempercepat perkembangan ASI pada ibu postpartum daripada intervensi LSA.

Saran Pijat oksitosin lebih efektif dalam mempercepat perkembangan ASI pada ibu nifas, oleh karena itu tenaga kesehatan khususnya bidan disarankan untuk menggunakan pijat relaksasi oksitosin sambil menawarkan aromaterapi uap Lavender sebagai metode alternatif untuk membantu ibu nifas mendorong produksi ASI

Kata Kunci: Aroma Terapi Lavender; Pijat Oksitosin; Produksi Air Susu Ibu

\section{PENDAHULUAN}

Air Susu Ibu (ASI) merupakan nutrisi alamiah bayi dengan kandungan gizi paling sesuai untuk pertumbuhan yang optimal. Begitu pentingnya memberikan ASI kepada bayi tercermin pada rekomendasi Organisasi Dunia (WHO) agar setiap bayi baru lahir mendapatkan ASI esklusif selama enam bulan. Manfaat pemberian ASI esklusif dalam hal menurunkan mortalitas bayi, mordibitas bayi, mengoptimalkan pertumbuhan bayi, membantu perkembangan kecedasan anak, dan membantu memperpanjang jarak kehamilan bagi ibu (Isnaini \& Diyanti, 2015).

Beberapa upaya untuk berhasil dalam memberikan ASI secara esklusif yaitu dengan diupayakan ibu yang sedang menyusui agar terhindar dari masalah kurang pengetahuan dan gangguan psikobgis yang mampu mempengaruhi keberhasilan Menyusui, Persiapan ibu secara psikobgis sebelum menyusui merupakan faktor paling yang mempengaruhi keberhasilan menyusui, stres, rasakuatir yang berlebihan, ketidakbahagiaan pada ibu sangat berperan dalam mensukseskan pemberian ASI esklusif (Lestari et al., 2018). Aroma terapi lavender merupakan salah satu metode inhalasi yang menggunakan aromaterapi, dampak positif aroma terapi lavender memberikan efek relaksasi pada systim syaraf pusat pada hipotalamus yang membantu meningkatkan produksi hormon oksitosin yang berdampak terhadap meningkatnya produksi ASI (Sarwinanti, 2014).

Selain itu Oksitosin adalah suatu hormon yang diproduksi oleh hipofisis posterior yang akan dilepas kedalam pembuluh darah jika mendapatkan rangsangan yang tepat.Efek fisiologis dari oksitosin akan mempunyai efek pada payudara yaitu akan melancarkan ASI dari kelenjar mamae.Pijat oksitosin ini dilakukan untuk merangsang refleks oksitosin (Delima et al., 2016). Manfaat pijat oksitosin juga memberikan kenyamanan pada ibu, mengurangi bengkak, mengurangi sumbatan ASI, mempertahankan produksi $\mathrm{ASI}$, selain itu dapat membuat rileks pada ibu nifas (Lestari et al., 2018).

Tujuan dari penelitian ini adalah untuk mengetahui Efektifitas Pemeberian Aromatherapi
Uap Lavender dan Pijat Oksitosin terhadap Produksi ASI pada Ibu Nifas di Puskesmas Kota makassar

\section{METODE PENELITIAN}

Jenis penelitian adalah penelitian komparatif untuk mencari perbandingan dua sampel atau dua uji coba pada obyek penelitian, dengan menggunakan pengukuran hanya dilakukan pada saat akhir penelitian. Penelitian di lakukan di Puskesmas Kota Makassar jumlah populasi dalam penelitian adalah 61 responden, Sedangkan jumlah sampel yaitu 30 sampel yang dibagi kedalam 2 kelompok yaitu 15 yang diberikan Intervensi Pijat Oksitosin dan 15 sampel yang diberikan Intervensi Aromaterapi Uap Lavender, adapun tekhnik Pengambilan sampel secara "Purposive Sampling". Kriteria inklusi dalam penelitian yaitu: Ibu Nifas dengan riwayat Persalinan pervaginam, Ibu nifas Primigravida, Ibu nifas yang menyusui bayinya, dan ibu nifas yang tidak memiliki kelainan payudara. Sedangkan kriteria eksklusi yaitu: Ibu nifas dengan riwayat asma, dan ibu nifas dengan kelainan genetik.

Teknik pengumpulan data yaitu data primer responden akan dibagi menjadi 2 kelompok sampel ada yang diberikan Intervensi Pijat Oksitosin dan diberikan intervensi Aromaterapu Uap Lavender, kelompok I (Pijat Oksitosin) dilakukan mulai post partum hari ke 4 setiap pagi dan sore selama 1 minggu, kemudian pada hari ke 10 Post partum (1 minggu ) diukur Produksi ASI dengan menggunakan alat pompa ASI atau Brust Pump. Sedangkan untuk kelompok intervensi 2 ( Aromaterapy Uap Lavender) dilakukan mulai post partum hari ke 4 setiap pagi dan sore selama 1 minggu, kemudian pada hari ke 10 Post partum (1 minggu) diukur Produksi ASI dengan menggunakan Brust Pump dan data sekunder dalam penelitian ini adalah data yang diperoleh dari Rekam Medis, Status Pasien yang melahirkan di Puskesmas Kota Makassar. Instrumen penelitian yang digunakan yaitu lembar observasi. Teknik analisa data yaitu analisa univariat Variabel peneliti dideskripsikan dan disajikan dalam tabel distribusi frekuensi dan 
JKM (Jurnal Kebidanan Malahayati),Vol 7,No.2.April 2021,

ISSN (Print) 2476-8944 ISSN (Online) 2579-762X, Hal 155-160

analisa bivariate dilakukan untuk mengetahui efektifitas aroma terapi uap Lavender dan Pijat Okstosin terhadap kelancaran produksi ASI dengan menggunakan uji $T$ - Independet.

\section{HASIL DAN PEMBAHASAN}

Dari hasil penelitian yang dilakukan pada puskesmas Kota Makassar diperoleh hasil sebagai berikut :

\section{Karakteristik Berdasarkan Umur}

Tahap analisis frekuensi presentasi variabel yang termasuk karakteristik responden yang dapat dilihat pada tabel 1 berikut ini :

Table 1.

Distribusi Frekuensi Responden Berdasarkan Karakteristik Ibu Nifas di Puskesmas Kota Makassar Sulawesi Selatan

\begin{tabular}{llcc}
\hline \multirow{2}{*}{ Karakteristik Responden } & \multirow{2}{*}{ Kategori } & \multicolumn{2}{c}{ Jumlah Responden } \\
\cline { 3 - 4 } & & $\mathbf{N}=\mathbf{3 0}$ & $\mathbf{\%}$ \\
\hline Usia & $<25$ Tahun & 8 & 27 \\
& $\geq 25$ Tahun & 22 & 73 \\
\multirow{3}{*}{ Tingkat Pendidikan } & SMP & 3 & 10 \\
& SMA & 20 & 67 \\
Pekerjaan & Sarjana & 7 & 23 \\
\multirow{2}{*}{ Propduksi ASI } & Bekerja & 13 & 43 \\
& Tidak bekerja & 17 & 57 \\
& PO : Banyak & 14 & 93.3 \\
& Sedikit & 1 & 6.7 \\
& AUL: Banyak & 12 & 80 \\
& Sedikit & 3 & 20 \\
\hline
\end{tabular}

Note: PO : Pijat Oksitosin

AUL: Aromaterapi Uap Lavender

Sedangkan hasil analisis bivariat menunjukkan bahwa terapi intervensi pijat oksitosin pada ibu nifas lebih efisien dalam perkembangan ASI dengan standar deviasi 6,60591 dibandingkan dengan intervensi aromaterapi uap lavender (SD = 9,74435).

Tabel 2.

Hasil bivariate Intervensi Pijat Oksitosin dan Relaksasi Aromatherapi Lavender

Terhadap Produksi ASI Pada Ibu Nifas di Puskesmas Kota Makassar

\begin{tabular}{lcccc}
\hline \multicolumn{1}{c}{ Intervensi } & $\mathbf{N}$ & Mean & $\boldsymbol{\rho}$ value & SD \\
\hline Pijat Oksitosin & 15 & 57.0667 & 6.60591 & \multirow{2}{*}{0,002} \\
AUL & 15 & 43.6667 & 9.74435 & \\
\hline
\end{tabular}

\section{PEMBAHASAN}

Intervensi pada 30 ibu postpartum yang mengalami penurunan produksi ASI menunjukkan hasil yang lebih baik pada 15 responden yang mendapatkan pijat oksitosin $(S D=6.60591)$. Hal tersebut sejalan dengan temuan penelitian yang dilakukan oleh Martini (2015), yang menawarkan pijat oksitosin kepada ibu nifas, meskipun nilai standar deviasi $(1,49)$ tidak jauh berbeda dengan kelompok kontrol $(1,42)$, tetapi pijat oksitosin masih lebih efektif dalam meningkatkan pemberian ASI pada ibu nifas. (Martini, 2015). Pijat oksitosin yang dilakukan di punggung ibu membawa kenyamanan bagi ibu. Secara fisiologis, ini mengaktifkan refleks oksitosin untuk mengeluarkan hormon oksitosin ke dalam darah. Oksitosin ini memungkinkan sel-sel mioepitel di sekitar alveoli berkontraksi dan menyebabkan ASI mengalir dari alveoli ke saluran ke dalam sinus dan puting susu dan bayi untuk menghisap. Semakin lancar pemrosesan ASI, semakin banyak ASI yang dihasilkan (Faridah, 2016). Hasil penelitian ini menunjukkan bahwa pada kelompok yang diberikan intervensi sebelum dilakukan pijat oksitosin (pre test) terdapat responden yang lancar ASI nya sebanyak 2 orang $(4.8 \%)$ dan yang tidak lancar ASI nya sebanyak 19 orang $(45.2 \%)$, kemudian setelah dilakukan pijat oksitosin (post test) terdapat responden yang lancar ASI nya sebanyak 18 orang (42.9\%) dan yang tidak lancar ASI nya sebanyak sebanyak 3 orang (7.1\%). Hasil uji menggunakan uji wilcoxon diperoleh nilai asymp zig $(0,000)<(0,05)$ sehingga dapat 
disimpulkan bahwa terdapat pengaruh signifikan pijat oksitosin terhadap produksi ASI pada ibu post partum di rumah sakit ibu dan anak siti fatimah makassar.(Arnyanti,2020). Menurut Yusari tahun 2018 meningkatkan kualitas pelayanan bagi tenaga kesehatan terutama bidan sebagai pelaksana sehingga dapat meningkatkan pengetahuan ibu akan pijat oksitosin dan dapat memotivasi ibu dan keluarga untuk melakukan pijat oksitosin dan memberikan bimbingan serta penyuluhan kepada ibu nifas tentang manfaat pijat oksitosin.

Pijat oksitosin merupakan salah satu prosedur non-farmakologis yang dapat dilakukan untuk memfasilitasi perkembangan ASI. Pijat dilakukan di sepanjang tulang belakang (vertebra) hingga tulang rusuk kelima-keenam (Martini, 2015). Oksitosin adalah hormon yang dapat membantu relaksasi, menurunkan tekanan darah dan kadar kortisol (hormon yang mempengaruhi stres) (Kamaruddin et al., 2019). Menurut Suryani 2013 Hasil Analisa bivariat menunjukan adanya perbedaan rata rata berat badan bayi dengan $p$ value : 0.001 ,ada perbedaan frekwensi BAK yang bermakna dengan $p$ value $=0,001$ dan ada perbedaan frekuensi menyusu yang bermakna dengan $p$ value $=0,001$ serta ada perbedaan lama tidur yang bermakna dengan $p$ value $=0,001$ ada pengaruh pijat oxytosin terhadap produksi ASI dengan indikasi berat badan bayi, frekwensi bayi menyusu, frekwensi bayi BAK dan lama bayi tidur setelah menyusu.Pijat Oksitosin memberikan kenyamanan pada punggung ibu(Wijayanti,2014). Punggung atas adalah titik digunakan untuk memperlancar proses laktasi. Saraf yang mempersarafi payudara berasal dari tulang belakang bagian atas, antara tulang belikat.Daerah ini adalah daerah dimana perempuan sering mengalami ketegangan otot(Fitri,2019)

Menurut Yanti 2019 bahwa pijat oksitosin berpengaruh terhadap produksi ASI pada ibu post partum. Hal ini karena dengan melakukan pijat oksitosin dapat merangsang hormon prolaktin dan oksitosin serta dapat melancarkan sirkulasi darah sehingga dapat mencegah penyumbatan saluran ASI. Dengan melakukan pijat oksitosin secara rutin pada ibu post partum maka akan melancarkan produksi ASI ibu. Pemberian pijat oksitosin oleh suami dapat meningkatkan produksi Air Susu Ibu (ASI) pada ibu nifas yang dilihat dengan berat badan bayi hari, frekuensi menyusui, lama tidur bayi, frekuensi Buang Air Besar bayi (BAB), frekuensi Buang Air Kecil bayi (BAK), dan istirahat tidur ibu.(Doko,2019).

Menurut Widiyanti,2014 ada perbedaan antara dilakukan pijatan oksitosin dan tidak dilakukan pijatan oksitosin terhadap produksi ASI pada ibu nifas di Wilayah Kerja Puskesmas Ambarawa. Produksi ASI pada ibu yang dilakukan pijat oksitosin lebih banyak dibandingkan ibu yang tidak dilakukan pijat oksitosin. Diharapkan bagi keluarga dan ibu post partum dapat melakukan tindakan pijat oksitosin dalam upaya peningkatan produksi ASI melalui petugas kesehatan.

Ibu dalam keadaan nyaman akan mendorong proses produksi ASI. Oksitosin memungkinkan sel mioepitel mengalir melintasi alveoli dan mengisi semua saluran susu dengan lancar (Apreliasari \& Risnawati, 2020; Erniawati \& Kamaruddin, 2020). Sebagian besar ibu nifas merasakan manfaat pijat oksitosin dimana produksi ASI sebelum dilakukan pijat oksitosin menjadi lancar setelah dilakukan pijat oksitosin.Hal ini juga membuat ibu merasa rileks, lebih nyaman, dan kelelahan setelah melahirkan juga berkurang.(Maita,2016)

Penggunaan minyak esensial aroma therapy lavender dapat membantu ibu untuk relaksasi dan kenyamanan sehingga diharapkan produksi ASI dapat meningkat(Tuti,2018). Aromaterapi lavender termasuk linalool dan linalyl acetate, yang memiliki efek antidepresan dan asiolitik (Koulivand et al., 2013). Lavender Dalam penelitian ini aromaterapi lavender sebagai intervensi untuk kelancaran perkembangan ASI pada ibu nifas menunjukkan standar deviasi sebesar 9,74 (Tabel 2). Namun perawatan aromaterapi lavender ini sangat ideal untuk relaksasi ibu nifas dengan mencapai peningkatan kualitas tidur yang signifikan. Berdasarkan Ramadhan (2017) dan Asiyah (2015), menghirup aromaterapi lavender mungkin memiliki efek relaksasi pada sistem saraf pusat hipotalamus, yang terletak di sistem saraf pusat, membantu meningkatkan perkembangan hormon oksitosin, yang berpengaruh pada peningkatan produksi ASI (Ramadhan \& Zettira, 2017). Selain itu, aromaterapi lavender juga dapat menyebabkan pelepasan oksitosin dengan memodifikasi homeostasis reseptor dopamin subtipe D3 dan proliferasinya. (Asiyah \& Wigati, 2015).

Dengan memberikan aromaterapi lavender melalui inhalasi mengaktifkan saraf penciuman dan bereaksi terhadap hipotalamus untuk mengaktifkan sistem limbik dan sistem hipofisis anterior sedemikian rupa sehingga kelenjar adrenal meminimalkan sekresi ACTH dan kortisol, menekan 


\section{JKM (Jurnal Kebidanan Malahayati),Vol 7,No.2.April 2021, ISSN (Print) 2476-8944 ISSN (Online) 2579-762X, Hal 155-160}

respon simpatis dan pelepasan asetilkolin dan meningkatkan sistem parasimpatis (Widyarti et al., 2020). Sehingga bisa memberikan efek relaksasi, penenang dan meningkatkan mood (Wulan, 2019). Minyak lavender untuk meningkatkan produksi ASI Ibu post partum(Sholihah,2017). Frekuensi produksi ASI sebelum diberikan aromatherapy lavender dan breastcare terbanyak dalam penelitian ini adalah produksi asi tidak lancar yaitu 16 responden atau sebesar 76,2\% dari keseluruhan responden. Frekuensi produksi ASI setelah diberikan aromatherapy lavender dan breastcare terbanyak dalam penelitian ini adalah produksi asi lancar yaitu 19 responden atau sebesar $90,5 \%$ dari keseluruhan responden. Adanya pengaruh produksi ASI pada ibu sebelum dan sesudah pemberian aromatherapy lavender dan breastcare dengan nilai $Z$ sebesar3.742 dengan $p$ value (asymp.sig 2 tailed) sebesar 0,000 ( $p$ value $<0,05$ ). (Hayati,2020)

\section{Menurut Putri 2021 Hasil penelitian menunjukkan perlakuan pijat punggung} menggunakan lavender adalah RR 3,33, artinya berisiko 3,33 kali meningkatkan produksi ASI. Hasil analisis multivariat menjadi 5 model pilihan karena terdapat kemaknaan dengan nilai pvalue $<0,05$, terjadi peningkatan $\mathrm{R} 2$ dan peningkatan OR. Model kelima adalah yang terbaik yang dipilih karena mampu menjelaskan produksi ASI sebesar 26\%.Pada saat kita menghirup suatu aroma, komponen kimianya akan masuk ke bulbus olfactory, kemudian ke system limbic pada otak.(Putri,2017).Pijat punggung menggunakan oil lavender ada pengaruh dengan pengeluaran ASI pada ibu post SC.(Vida,2014). terdapat perbedaan durasi relaktasi antara ibu yang diberikan kombinasi pijat oksitosin dan aromaterapi lavender dan yang tidak diberikan (kontrol) dengan relaktasi metode suplementer.(Putri,2016)

Berdasarkan temuan penelitian ini, dapat disimpulkan bahwa pijat oksitosin dan aromaterapi uap Lavender sama-sama dapat memberikan efek relaksasi pada ibu nifas, namun efikasi produksi ASI lebih cepat dan lebih tinggi dengan Oxytocin Massage. Hal ini dikarenakan ibu dalam keadaan rileks yang akan memudahkan produksi ASI. Oksitosin membantu sel-sel mioepitel di sekitar alveoli untuk mengalir dan mengisi saluran susu dengan lancar, sehingga aromaterapi uap Lavender yang menenangkan melewati proses penghirupan dan mengaktifkan saraf penciuman dan kemudian bereaksi terhadap hipotalamus..Setiap tenaga kesehatan khusunya perawat dan bidan hendaknya mengaplikasikan pijat oksitosin menggunakan minyak esensial lavender untuk melancarkan produksi ASI.(Cahyanti,2017)

\section{SIMPULAN}

Relaksasi pijat oksitosin dan aromaterapi uap lavender untuk ibu nifas pada aliran ASI di Puskesmas Makassar, Sulawesi Selatan, keduanya memiliki efek relaksasi dan membantu ibu nifas melancarkan ASI.

\section{SARAN}

Pijat oksitosin lebih efektif dalam mempercepat perkembangan ASI pada ibu nifas, oleh karena itu tenaga kesehatan khususnya bidan disarankan untuk menggunakan pijat relaksasi oksitosin sambil menawarkan aromaterapi uap Lavender sebagai metode alternatif untuk membantu ibu nifas mendorong produksi ASI.

\section{UCAPAN TERIMA KASIH}

Kami mengucapkan terima kasih atas dukungan Direktorat Riset dan Pengabdian kepada Masyarakat, Direktorat Jenderal Riset dan Pengembangan, Kementerian Riset, Teknologi, dan Pendidikan Tinggi Republik Indonesia yang telah mendukung melalui Program Hibah Riset tahun 2020. Kami mengapresiasi Universitas Megarezky dan Puskesmas Makassar, Sulawesi Selatan atas pelayanan, bantuan dan kerjasama dalam penelitian ini. Selain itu terima kasih kepada Program Studi Magister Teknologi Laboratorium Medik Universitas Muhammadiyah Semarang atas partisipasinya dalam publikasi.

\section{DAFTAR PUSTAKA}

Apreliasari, H., \& Risnawati. (2020). Pengaruh Pijat Oksitosin terhadap Peningkatan Produksi ASI. JIKA, 48-50.

Arniyanti, A., \& Angraeni, D. (2020). Pengaruh Pijat Oksitosin Terhadap Produksi ASI Pada lbu Post Partum Di Rumah Sakit Khusus Daerah Ibu dan Anak Siti Fatimah Makassar. Jurnal Mitrasehat, 10(1), 1-11.

Asih, Y. (2018). Pengaruh Pijat Oksitosin terhadap Produksi ASI pada Ibu Nifas. Jurnal IImiah Keperawatan Sai Betik, 13(2), 209-214.

Asiyah, N., \& Wigati, A. (2015). Minyak Aromaterapi Lavender sebagai Media Peningkatan Produksi ASI. JIKK, 23-38. 
Cahyanti, B. R., Mursudarinah, M., \& Andriyani, A. (2017). PENERAPAN PIJAT OKSITOSIN MENGGUNAKAN MINYAK ESENSIAL LAVENDER UNTUK MELANCARKAN PODUKSI ASI IBU POST PARTUM PRIMIGRAVIDA DI DESA PAMEDAN TIMUR KOTA SURAKARTA.

Doko, T. M., Aristiati, K., \& Hadisaputro, S. (2019). Pengaruh Pijat Oksitosin oleh Suami terhadap Peningkatan Produksi Asi pada Ibu Nifas. Jurnal Keperawatan Silampari, 2(2), 66-86.

Delima, M., Arni, G. Z., \& Rosya, E. (2016). Pengaruh Pijat Oksitosin terhadap Peningkatan Produksi ASI. Jurnal Ipteks Terapan: Research of Applied Science and Education, 283-293.

Erniawati, \& Kamaruddin, M. (2020). Asuhan Kebidanan Pasca Salin (1st ed.). Manggu Makmur Tanjung Lestari.

FITRI, A. S. (2019). PENGARUH PIJAT PUNGGUNG TEKNIK EFFLEURAGE MENGGUNAKAN MINYAK AROMATERAPI LAVENDER TERHADAP PRODUKSI ASI IBU POST PARTUM DI KLINIK PRATAMA TANJUNGDELI TUA TAHUN 2018.

Fitri, L. (2016). Pengaruh Pemberian Kombinasi Pijat Oksitosin Dan Aromaterapi Lavender Terhadap Durasi Relaktasi Dengan Suplementer Di Malang Raya (Doctoral dissertation, Universitas Brawijaya).

Hanum, S. M., Purwanti, Y., \& Khumairoh, I. R. (2015). Efektifitas Pijat Oksitosin terhadap Produksi ASI. Midwiferia, 1-6.

Hayati, L., Distinarista, H., \& Wahyuni, S. (2020). PENGARUH AROMATHERAPY LAVENDER DAN BREASTCARE (PERAWATAN PAYUDARA) TERHADAP PRODUKSI ASI IBU POSTPARTUM DI RSI SULTAN AGUNG SEMARANG. Prosiding Konferensi IImiah Mahasiswa Unissula (KIMU) Klaster Kesehatan.

Isnaini, N., \& Diyanti, R. (2015). Hubungan Pijat Oksitosin pada lbu Nifas terhadap Pengeluaran ASI di Wilayah Kerja Puskesmas Raja Basa Indah Bandar Lampung Tahun 2015. Jurnal Kebidanan, 91-97.

Kamaruddin, M., Rawe, A. T., Asra, A., \& Marzuki, I. (2019). Kepercayaan Terhadap Kemampuan Budaya Bengkung dalam Meningkatkan.
Seminar Nasional Pangan, Teknologi, dan Enterpreneurship (pp. 476-479). Makassar: Gertasi, Adpertisi.

Koulivand, P. H., Ghadiri, M. K., \& Gorji, A. (2013). Lavender and the Nervous System. Evidence-Based Complementary and Alternative Medicine, 1-10.

Lestari, L., Melyana, N. W., \& Admini. (2018). Peningkatan Pengeluaran ASI dengan Kombinasi Pijat Oksitosin danTeknik Marmet. Jurnal Kebidanan, 1-10.

Maita, Liva. "Pengaruh pijat oksitosin terhadap produksi ASI." Jurnal Penelitian Kesehatan" SUARA FORIKES"(Journal of Health Research" Forikes Voice") 7, no. 3 (2016): 173-175.

Martini, D. E. (2015). Efektifitas Pijat Oksitosin terhadap Peningkatan Produksi ASI pada lbu. Surya, 20-25.

Mastuti, N. L. P. H., Hastuti, N. A. R., \& Lovita, A. N. D. (2017). Pengaruh Relaktasi Suplementer Dikombinasikan dengan Pijat Oksitosin dan Aromaterapi Lavender terhadap Peningkatan Berat Badan Bayi di Malang Raya. Journal of Issues in Midwifery, 1(2), 76-81.

Putri, S. R. (2021). Efektifitas Pijat Oksitosin dan Aromaterapi Lavender terhadap Keberhasilan Relaktasi pada lbu Nifas. Jurnal IImu Kesehatan Masyarakat, 10(01), 1-7.

Putri, L. W. (2017). PENGARUH PIJAT PUNGGUNG MENGGUNAKAN MINYAK ESENSIAL LAVENDER TERHADAP PRODUKSI ASI PASCA BEDAH SESAR DI RUANG AYUB I RUMAH SAKIT ROEMANI MUHAMMADIYAH SEMARAH (Doctoral dissertation, Universitas Muhammadiyah Semarang).

Ramadhan, M. R., \& Zettira, O. Z. (2017). Aromaterapi Bunga Lavender (Lavandula angustifolia) dalam Menurunkan Risiko Insomnia. Majority, 60-63.

Sarwinanti. (2014). Terapi Pijat Oksitosin Meningkatkan Produksi ASI pada lbu Post Partum. Jurnal Kebidanan dan keperawatan, 47-53.

SHOLIHAH, A. M. A. (2017). PENERAPAN TEKNIK MARMET DAN PIJAT OKSITOSIN DENGAN MINYAK LAVENDER UNTUK MENINGKATKAN PRODUKSI ASI IBU POST PARTUM DI BPM HJ. N. LUSI SUMARTINI, S. ST KEDAWUNG (Doctoral 
JKM (Jurnal Kebidanan Malahayati),Vol 7,No.2.April 2021,

ISSN (Print) 2476-8944 ISSN (Online) 2579-762X, Hal 155-160

dissertation, STIKES MUHAMMADIYAH GOMBONG).

Suryani, E., \& Astuti, K. E. W. (2013). Pengaruh pijat oksitosin terhadap produksi ASI ibu postpartum di BPM Wilayah Kabupaten Klaten. Interest: Jurnal IImu Kesehatan, 2(2).

Vidayanti, V. (2014). Pengaruh Pijat Punggung Menggunakan Minyak Esensial Lavender Terhadap Produksi ASI Pasca Bedah Sesar di RSUD Panembahan Senopati bantul (Doctoral dissertation, Universitas Gadjah Mada).

Widiyanti, F. A., Setyowati, H., Sari, K., \& Susanti, R. (2014). PERBEDAAN ANTARA DILAKUKAN PIIJATAN OKSITOSIN DAN TIDAK DILAKUKAN PIJATAN OKSITOSIN TERHADAP PRODUKSI ASI PADA IBU NIFAS DI WILAYAH KERJA PUSKESMAS AMBARAWA. In Prosiding seminar nasional \& internasional (Vol. 2, No. 2).

Widyarti, S., Kamaruddin, M., Aristyani, S., Elvina, M., Subagjo, S., Rahayu, T., \& Sumitro, S. B.
(2020). Bioinorganic Chemistry and Computational Study of Herbal Medicine to Treatment of Tuberculosis. In Medicinal Plants - Use in Prevention and Treatment of Diseases (pp. 1-20). England: IntechOpen.

Wijayanti, L. (2014). Pengaruh Pijat Oksitosin Terhadap Produksi ASI Pada lbu Post Partum di Puskesmas Mergangsan Yogyakarta Tahun 2014 (Doctoral dissertation, STIKES'Aisyiyah Yogyakarta).

Wulan, M. (2019). Pengaruh Kombinasi Pijat Oksitosin Dengan Aromaterapi Lavender. Jurnal Teknologi, Kesehatan dan IImu, 1726.

Yanti, M. S. (2019). Pengaruh Pijat Oksitosin Terhadap Produksi ASI Pada lbu Post Partum Di BPM Meli R. Palembang Tahun 2018. Jurnal Kesehatan dan Pembangunan, $9(17), 37-46$. 